Article

\title{
Advantages and Disadvantages of Warehouse Centralization - Hospital Case
}

\author{
Jorge Simões ${ }^{1, *}$, Jorge Cartaxo ${ }^{2}$, Rúben Loureiro ${ }^{3}$, Bruno Santos ${ }^{4}$ and Sílvio Silva ${ }^{5}$ \\ 1 Polytechnic Institute of Tomar, Tomar, Portugal and CIAEGT (Centro de Investigação Aplicada em \\ Economia e Gestão do Território); jorgesimoes@ipt.pt; \\ 2,3,4,5Polytechnic Institute of Tomar, Tomar, Portugal; jota_cartaxo@hotmail.com; ruben.loureiro@hotmail.com; \\ bruno.almeidasantos@ipt.pt; silviovsilva@ipt.pt. \\ * Correspondence: jorgesimoes@ipt.pt; Tel.: +35-249-328-100
}

\begin{abstract}
In the area of health, namely hospitals, we can agree that the intrinsic need to have multidisciplinary teams, highly specialized and indispensable resources leads us to a degree of complexity that requires, daily, the best performance, not running away from the logistics area to the rule. The centralization of resources, namely distribution warehouses, emerges as a challenge and possible solution for health institutions to respond in the best possible way to their main purpose: to put the right material in the right place at the right price in the right time space. As regards the advantages of this type of organization, there are several authors who argues that the need for human resources training, ease of coordination and the use of economies of scale are the main advantage. As far as the disadvantages are concerned, there is no special agreement on them, there are disparate factors from author to author, such as: routine, centralization, objectives or operation costs.
\end{abstract}

Keywords: Logistics; Logistical Centralization; Logistical Decentralization

\section{Introduction}

The approach to the centralization or decentralization of resources in institutions assumes diverse perspectives, which makes it one of the most controversial topics in Organizational Theory. We must realize that these concepts rather than nomenclatures for the way an institution is organized are rather an organizational spectrum that goes far beyond physical space, since there can be centralization or decentralization at different levels (transportation, operational coordination or decision making, for resource centralization, centralization of services or decision-making power) [11]. In other words, decentralization or centralization of resources generally affects pooling of resources.

When addressing the issue of centralization we can do so from different perspectives such as analysis of back office issues such as the case of purchases or otherwise make an operational approach that offers us answers at this level (stock management and storage, distribution or transport of materials). However, if we design a health institution, we have to realize that the fact that it is made up of multidisciplinary teams with different degrees of specialization, which provide the capacity to meet their existing needs, also leads to their high degree of specialization orient to the goals forgetting that only their joint action will lead to each one of the areas have the success that they want.

Looking at the path followed by health institutions that are aligned with the methodology of centralization of resources, we must analyze that the implementation of centralization is related to the various advantages that bring competitive factors to large institutions - case of the Hospitals' Centers, EPE - allowing them to more easily control the operational processes related to the logistics 
activity, promoting these same activities and unifying the institution (be it infrastructure, management or operational).

\section{Advantages and Disadvantages of Warehouse Centralization}

Looking at the work of [11] and [8], this tells us that there are factors, called contingency factors, in which the relationship between these defines us the structure of the organization, and when we speak of centralization of resources in a hospital context it is extremely important to understand how institutions are organized and how their structure can be designated, so the authors defines as main contingency factors:

- The age and size of the organization, as institutions age and grow or reduce formality and their organization is affected, with smaller and smaller organizations tending to be less formal and, on the contrary, organizations larger and older tend to have more hierarchical levels and greater degree of formality;

- The technical system, technology influences the way organizations are structured being that in addition to the effect at the operational level also has effects on management level, for example in the case of routine tasks in which there is no motivation of the professionals and that its automation leads to the absence of pressure from management to obtain results;

- The environment can be characterized, essentially by four variables, stability, an institution can be more dynamic or more static, complexity, related to the type of activity, the diversity of markets, and the activity can be directed to a single target or be broader and ultimately hostility may be more hospitable or hostile, depending on existing relationships and the very activity that develops;

- Power, the influence of power manifests itself through existing external control, organizations run by large groups (eg, public sector) tend to have a greater degree of centralization, and it also influences the need for power and the adoption of organizational structures just by fashion.

According to [6], [9] and [10] there are factors that differentiate institutions and give them unique characteristics in which a process of centralization would be a factor that promotes more harm than benefits (or vice versa), we have to look globally for centralization and decentralization, taking into account that this approach can be carried out from different perspectives, either in a centralized view of the operational process (physical centralization) or in a management perspective (centralization of decision-making power) by observing its advantages the advantages for one are disadvantages for the other) as shown in table 1 :

Table 1. Advantages of Centralization and Decentralization

Advantages of Centralization

Quality in decision making

Lower training needs

Standardization of work standards and instructions

Coordination Facility

Efficient performance of expert work

Identification of intermediate collaborators with the least determinant organization

Use of economies of scale
Advantages of Decentralization

Activity centered on results

Intermediate-level employees with greater involvement

Collaborators with greater involvement with the organization's objectives

Increased internal competition

Easier evaluation of the activity developed

Minor workflow

Most formative training tool at training level 
These advantages, when properly exploited, provide institutions with greater competitiveness, optimization of resources and increasing their capacity to adapt to the constant challenges posed to them [1] and [7].

As discussed in the introduction, there is a need to realize that, for most authors, what is considered to be the advantage of a structure with a higher level of centralization is, on the contrary (mostly), a disadvantage for a structure with a higher level of decentralization, in this way we will assume this analysis from the perspective of centralization, considering that for institutions with a higher level of decentralization the analysis is done in the opposite way [9] and [10].

For [5], in a study based on the military reality (US Army), there is a need to perceive the latent needs in the institution so that it can define the best structure it should adopt at its various organizational levels. Both the rapid performance and the efficiency of this in the operationalization and the decision making are directly linked to institutions with higher levels of centralization, providing these of lower hierarchical levels (which leads to a lower amount of analysis), which serves as a facilitating factor process speed [5].

Centralization, however, entails some negative points, all related to the fact that in institutions, with a higher level of centralization, hierarchical levels exist in a smaller number, which promotes the application of specific knowledge and at the same time decision making in a small number of employees, there is a greater probability that the functions performed are more routine (operational focus). When we speak of decision-making power, we must be aware that the reduction of hierarchical levels, besides decreasing the number of decision levels, centralizes the same one, so that, on the one hand, in common situations the decision is made quickly, but On the other hand, in specific cases, and not so frequent, it may become more time-consuming [5].

It should be noted that for these authors, risk is a negative point in unbalanced structures (that is, in the organizational spectrum they tend more to one side, centralized or decentralized), because there are very large or very small levels of analysis of a decision to be taken erroneously because it is centralized or mistakenly taken down by a lower level (tending to a lesser degree of specialization) without a higher hierarchical level having immediate knowledge [5].

In the study developed by [9] and [10] we can summarize this parameter of analysis to the dichotomy between centralization and decentralization, in a very different way, in which the focus is not only on decision making but also on aspects that may arise from level of centralization.

The work presented by the authors leads us to realize that the main advantages are threefold: decision making (quality and speed), operational and management coordination, and qualification / training of the professionals that make up the work team [10]. On the other hand, from the point of view of the advantages of decentralization (disadvantage from the point of view of centralization) we perceive that the incidence also goes through three factors: results (and their evaluation), internal competition and workflow analysis [10]. Thus the advantages in disadvantages have as factors that are easily influenced by the constitution of work teams, physical conditions (infrastructures / transports) and work processes, that is, the organization of the institution functions as a "lever" or "brake" depending on the perspective that this subject is addressed.

If we look at the work developed by [1] we can see that the starting point of this one with regard to the advantages of centralization is essentially two vectors:

- Number of hierarchical levels;

- Specialization of decision makers.

In centralized structures there is a greater distance between decision makers and the problems of each unit, since it is a horizontal structure in which the decision maker has responsibility for a greater number of "problems", in which case the decision maker has which, in spite of its specific area of activity, generally dominates all the areas on which it must take the decision [1]. 
On the other hand, in tendentially decentralized structures there is a greater level of segregation of decision making and therefore more levels of decision making and analysis until it is made, making its analysis more elaborated and in this case the decision makers are increasing importance at the hierarchical level [1].

Also [1], referring to the investigations of [4] and [5], presents the different perspectives of how the centralization can be beneficial or harmful to an institution through its sector of activity and way of acting.

By listing various authors and perspectives on how centralization can be considered for institutions, it is possible to gather information that determines to us, in relation to the other authors, factors that go to the heart of the matter with regard to the management of institutions (whether private or public) the efficient and effective allocation of resources [1].

We can then define as advantageous for the institutions that adopt a tendentially central institution the following points:

- Purchasing, by having the capacity to negotiate in greater quantitative volume, the client endows himself with power over the supplier;

- Work policies by promoting centralized work policies and horizontal organizational structures in which decision-making power and the level of specializations are at the top of the hierarchy, there is a greater control of functions and a work balance in the lower hierarchy;

- Management, central administration with associated costs, that is, being the management organized in this typology exists the ability to anticipate costs with it;

- Receiving / storing goods, allows reduction of stocks and increases the capacity of response, since the centralization of the stocks and the passage to a reality in which the volume and flow of circulation of materials is much greater, there is the possibility of:

- Have a lower optimum order point, which therefore leads to smaller minimum stock; More reliable demand analysis and, in turn, more efficient stock management; Effective and efficient stock management control, since the quantities in stock, share the same reception, storage and dispatch / distribution space;

- Decreased dependence between distributor and shipper, by centralizing storage and providing the distribution points of a point of attachment to each other, there is a possibility of moving materials more easily.

On the other hand, a centralized logistical process causes some drawbacks that should, can and should be minimized, such as:

- Suspension of supply by suppliers, when purchasing large quantities and having preferred suppliers, in the event of failure of these, there is a possibility of material breakage;

- Deterioration of materials, such as in storms or inclement weather, centralization of material storage has the disadvantage that any damage to the stock will affect, in theory, a large part or all of them;

- Operational costs, the option of centralization in the logistics area entails a high level of investment both in its initial phase and in its maintenance, such as infrastructures, distribution channels or information systems;

- Integration of the various distributors (standardized methodology), in case the institution does not centralize all its distribution channels and these are not governed by the established methodology, is a hindrance to their integration;

- Changes to the logistic system implemented, from the point of view of information systems and work methodologies, its change after implementation is a factor that promotes the increase of costs in the institution. 
Briefly, we can present the advantages (table 2) and disadvantages (table 3) of the resource centering in the logistics area (and to relate the different opinions):

Table 2. Advantages of centralization

\section{Authors}

\begin{tabular}{lccc} 
& [5] & [1] & [10] \\
\hline Velocity & X & & \\
Efficiency & $X$ & & \\
Quality decision making & & X \\
Training needs & $X$ & $X$ \\
Standards and Work Instructions & & $X$ \\
Coordination & $X$ & $X$ \\
Specialist Work & & $X$ \\
Identification with Institution & & $X$ \\
Scale economy & & $X$ \\
Responsiveness & $X$ & $X$ \\
Dependency & $X$ & \\
\hline
\end{tabular}

So with regard to the advantages, and considering that the area to which the studies refer can influence their analysis, we can consider that there is agreement on the need for training by human resources, the ease of coordination and to the capacity that enables organizations in the procurement processes to be able to utilize economies of scale.

In the following table, 3 , we present the disadvantages that the different studies presented suggest us, and if in terms of the advantages the authors can find common lines of thought in the disadvantages does not happen the same.

Table 3. Disadvantages of centralization

\section{Authors}

[5]

[1] [10]

\begin{tabular}{|c|c|c|c|c|}
\hline \multirow{15}{*}{ 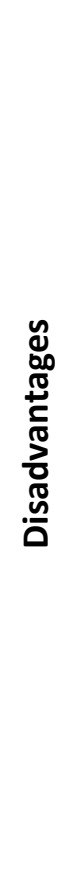 } & Fragility & $x$ & & \\
\hline & Routine & $x$ & & \\
\hline & Risk & $x$ & & \\
\hline & Centralization Results & & & $x$ \\
\hline & Intervention Intermediate collaborators & & & $x$ \\
\hline & Centralization Objectives & & & $x$ \\
\hline & Competition & & & $x$ \\
\hline & Evaluation & & & $x$ \\
\hline & Workflow & & & $x$ \\
\hline & Training Facility & & & $x$ \\
\hline & Suspension Supply & & $x$ & \\
\hline & Detection Materials & & $x$ & \\
\hline & Costs Operationalization & & $x$ & \\
\hline & Standardized Methodology & & $x$ & \\
\hline & Logistics System & & $x$ & \\
\hline
\end{tabular}




\section{Applicability of the Centralization Concept to the Health Sector}

The hospital environment and its own environment means that, in a very natural way, there is a need to define priorities, apply and manage resources in a very peculiar and fast way, never jeopardizing the safety of the user, providing the best and necessary medical care at the right time, as well as the optimization of them [13].

Thus, the production process in a hospital context causes all areas, at all times, to be influential in a positive way or in a negative way, being that in this way the logistics area is one that directly poses greater constraints to the management hospital [12] and [15].From the beginning of the process (identified need) until consumption to the user (when we speak of consumption to the user we speak of the provision of care, not from the perspective of billing to the user) there are several steps that can, in a simple way, despite their complexity, affect the hospital production process.

In order to exemplify how the logistics area can be applied to the health sector, especially in a hospital context, we can observe the following figure 1 where the material circuit will be presented inside a warehouse, where it is perceived that all the steps / processes are common between the business and the hospital.
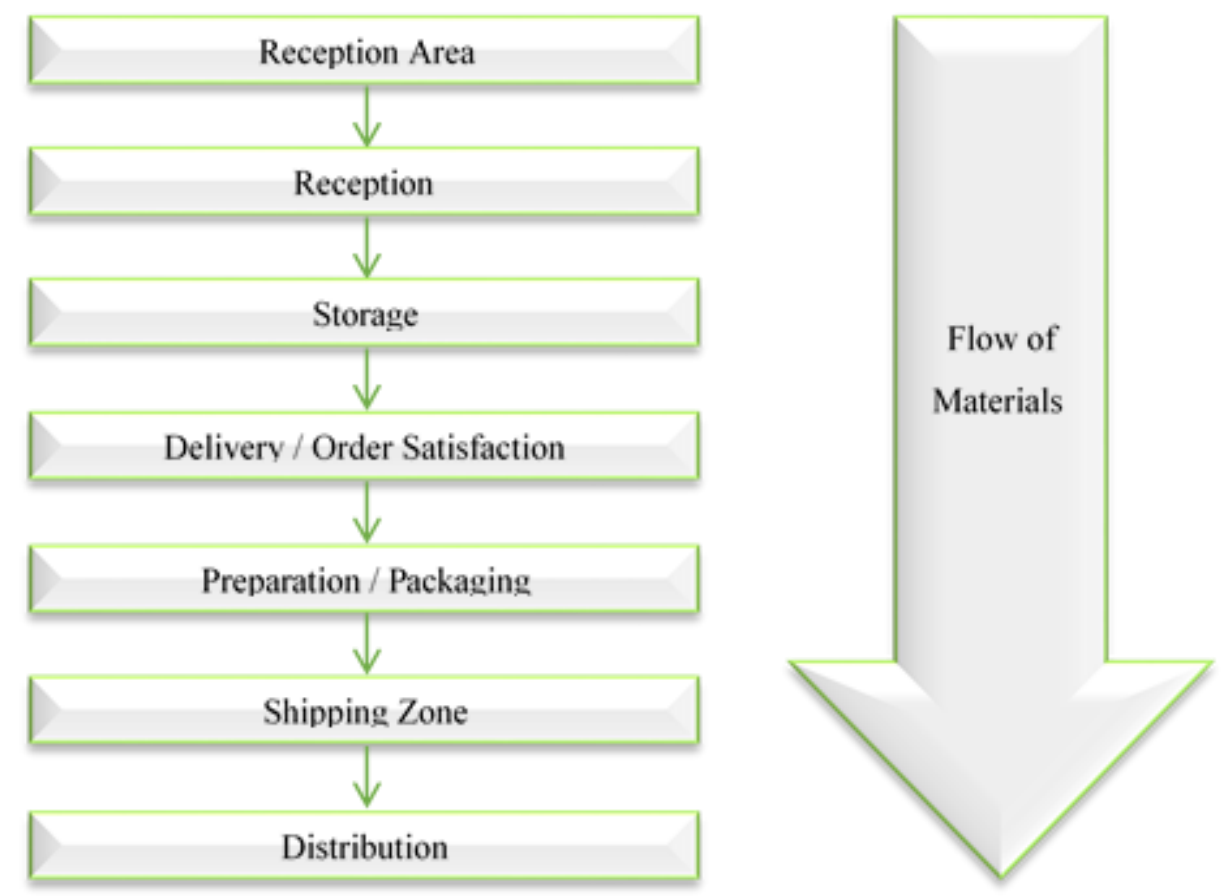

Figure 1. Flow of Materials in a Distribution Warehouse

${ }^{1}$ Adapted from [14]

If we analyze the previous illustration we see the flow of goods inside a warehouse from the time it is received until it is distributed / delivered at the point of consumption / sale and we realize that this circuit is not only applicable to a specific sector, but to all those who distribution (receipt of finished products and distribution of them at their points of consumption).

In the background, establishing a relationship between the logistics area and the health area, as well as the applicability in this branch of activity, turns out to be redundant given the obvious need, as already mentioned, of whatever the developed activity there is a support, with functions that are perfectly delineated and which give it the ability to respond to identified needs [3].

Thus, we may consider it pertinent to focus on two principles:

1. To perceive the circuit as a whole, so that the performance evaluation is as correct as possible and not only performed on an aspect that makes up the circuit from the entrance to the exit of the user of the health institution [2]; 
2. To perceive that the user is the main factor on which health institutions perform their activity, and often the care that the user needs and those he or she expects to receive from the service are not similar [2].

Thus efficiency, effectiveness, productivity or profitability are concepts that allow us to perceive that the logistics system of institutions has a large share in what care is provided and a small flaw in its flow can promote the existence of errors, which, in the limit, will influence the quality of the services provided and thus influence the results that are desired [2], [5] and [11].

\section{Conclusions}

The health sector is framed by a paradigm shift that Health Institutions must follow, where changes in policies, methods and management systems will necessarily have to be done in an innovative way and that will have a positive impact on the public- target [12] and [16].

We must then, with due caution, be aware of the reality of the institution that we are working not only from the point of view of its contextual environment but also the resources it has available so that we can, in a clear, concise and objective way, the way of using the various theories of the logistics area in the institution and, if possible, moving towards a centralization scenario.

According to [1], it is important to understand the issue of centralization as something dynamic and constantly changing given the dependence that this process presents on its most varied fronts. For centralization has to be understood as a spectrum of institutions in which institutions may be "more" or "less" centralized, for example, a certain service may be centralized in a particular infrastructure, but its management model may be different for different areas which support it.

A simple and complete way of understanding the potential importance of centralizing resources for institutions is to analyze the different approaches (from different authors) to the advantages and disadvantages of this theme. Thus, in the developed article, the approaches developed by [1], [5] and [10] were listed. With regard to the advantages that have been gathered, we can highlight that it is common to the authors to evaluate them according to the type of institution they are targeting, so once again, it is important to highlight that the subjectivity that the topic of centralization can cause is demonstrated its dynamic character. However, in the more recent studies (and being organized in order of importance for the subject of research), there is a greater degree of agreement regarding this aspect, and through centralization the hierarchical structure will be, decision and expertise levels are centralized, thus promoting:

\section{Low training needs;}

2. Easier coordination of the institution's various players.

It is also consistent that the centralization of resources in the logistics area promotes the ability to work with economies of scale (when dealing with goods) given the increase in existing workflow, which, therefore, provides the institutions with a greater negotiating capacity together of suppliers.

When we look at the disadvantages the level of disagreement is even greater, there is no common point between authors, so it should be mentioned that once again are shown how this topic can be approached from several perspectives and especially from different areas. As for example the needs of a military institution will be, for the most part, different from those of a health institution, and thus the assessment of the logistics area is necessarily different. Thus, through the analysis of advantages and disadvantages, rather than listing them, it is necessary to understand that this analysis is not only subject to the subjectivity of the person who does it, but above all to the area to which it refers, whether it is business or public.

\section{References}

1. Carvalho, J. A Lógica da Logística, 1rd ed.; Sílabo: Lisboa, Portugal, 2004, 9789726183372.

2. Carvalho, J.; Ramos, T. Logística na Saúde, 1rd ed.; Sílabo: Lisboa, Portugal, 2016, 978-972-618-844-5. 
3. Carvalho, J.; Guedes, A.; Arantes, A.; PaulaPóvoa, A.; Luís, C.; EuricoDias, T. Logística e Gestão da Cadeia de Abastecimento, 1rd ed.; Sílabo: Lisboa, Portugal, 2017, 978-972-618-894-0.

4. Fernie, J. Retail distribution management: a strategic guide to developments and trends, 1rd ed.; Kogan Page: London, United Kingdom, 1990, 0749400307.

5. Fukuyama, F.; Shulsky, A. The "Virtual Corporation" and Army Organization, 1rd ed.; RAND: Santa Mónica, United States, 1997, 9780833025326.

6. Hemilä, J.; Vilko, J. The development of a service supply chain model for a manufacturing SME. The International Journal of Logistics Management 2015, 26, 3, pp .517-542, 10.1108/IJLM-01-2014-0001.

7. Kasarda, J.D. Logistics Is about Competitiveness and More. Logistics 2017, 1, 1, 10.3390/logistics1010001

8. Knoppen, D.; Johnston, D.; Sáenz, M. Supply chain relationships as a context for learning leading to innovation. The International Journal of Logistics Management 2015, 26, 3, pp. 543-567, 10.1108/IJLM-09-2012-0089.

9. Kriegel, J.; Jehle, F.; Dieck, M.; Mallory, P. Logist. Research 2013, 6, 47, 10.1007/s12159-013-0100-x.

10. Mendes, G. S.; Theis, V.; Fagundes, C.; Schreiber, D.; Oliveira Da Silva, M. Logística Reversa: Estudo de Caso em Uma Indústria de Artefatos Plásticos. Exacta 2016, 14, pp. 37-45, 10.5585/exactaep.v14n1.6110.

11. Mintzberg, H. Estrutura e Dinâmica das Organizações, 4rd ed.; Dom Quixote: Lisboa, Portugal, 2010, 9789722040006.

12. Morais, L. Liderança e Estratégia - Casos de Inovação nas Organizações de Saúde, 1rd ed.; Escolar Editora: Lisboa, Portugal, 2012, 9789725923375.

13. Ramos, S.; Trindade, L. Gestão do risco: Segurança do doente em ambiente hospitalar. Tecno Hospital 2011, 48, pp. 16-20.

14. Rodrigues, G.; Pizzolato, N., Centros de Distribuição: Armazenagem Estratégica, Proceedings of XXIII Encontro Nac. de Eng. de Produção, Minas Gerais, Brazil, 21-24 October, 2003, pp. 1-3.

15. Xiong (Thomas) Pan, Z.; Pokharel, S. Logistics in hospitals: a case study of some Singapore hospitals. Leadership in health services 2007, 20, pp. 195-207, 10.1108/17511870710764041. 